REFLEKSI EDUKATIKA : Jurnal Ilmiah Kependidikan Volume 9 Nomor 2 Juni 2019

ISSN: 2087-9385 (print) dan 2528-696X (online) http://jurnal.umk.ac.id/index.php/RE

\title{
MITOLOGI SEBAGAI PENDIDIKAN KEBENCANAAN DALAM MEMAHAMI ERUPSI GUNUNG MERAPI
}

\section{Septian Aji Permana ${ }^{1}$, dan Supri Hartanto ${ }^{2}$}

Universitas PGRI Yogyakarta ${ }^{1,2}$

Email: aji@upy.ac.id

\begin{tabular}{|c|c|}
\hline Info Artikel & Abstract \\
\hline $\begin{array}{l}\text { Sejarah Artikel: } \\
\text { Diterima 8 April } 2019 \\
\text { Direvisi 28 Mei } 2019 \\
\text { Disetujui 28 Mei } 2019\end{array}$ & $\begin{array}{l}\text { This study aims to analyze community culture in understanding the eruption of Mount Merapi } \\
\text { and analyze the meaning of education implied in the mythology of Mount Merapi. This study } \\
\text { uses a qualitative approach. The informants in this study were the Cangkringan community, the } \\
\text { caretaker of Mount Merapi, the NGO (Non-Governmental Organization) Cangkringan. Data } \\
\text { collection techniques are carried out by participant observation and in-depth interviews. The } \\
\text { collected data is then analyzed using domain, taxonomic, compound, and cultural theme analysis }\end{array}$ \\
\hline $\begin{array}{l}\text { Keywords: } \\
\text { Mitologi, Pendidikan } \\
\text { Kebencanaan, Kearifan, Erupsi } \\
\text { Merapi. }\end{array}$ & $\begin{array}{l}\text { The findings in the form of public trust in Mount Merapi that people believe Mount Merapi is } \\
\text { inhabited by supernatural beings who should have a life like humans. The supernatural beings } \\
\text { have their own organization that regulates the government hierarchy with all its attributes and } \\
\text { activities. One form of government hierarchy of supernatural beings that is closely related to } \\
\text { society is that people believe that Mount Merapi is a Palace of Fine Beings. }\end{array}$ \\
\hline
\end{tabular}

\begin{abstract}
Abstrak
Penelitian ini bertujuan untuk menganalisis budaya masyarakat dalam memahami erupsi Gunung Merapi dan menganalisis makna pendidikan yang tersirat didalam mitologi Gunung Merapi. Penelitian ini menggunakan pendekatan kualitatif. Informan dalam penelitian ini yakni masyarakat Cangkringan, juru kunci Gunung Merapi, LSM (Lembaga Swadaya Masyarakat) Cangkringan. Teknik Pengumpulan data dilakukan dengan observasi secara partisipan dan wawancara secara mendalam. Data yang terkumpul kemudian dianalisis dengan menggunakan teknik analisis domain, taksonomik, komponensial, dan tema kultur.

Hasil temuan berupa kepercayaan masyarakat terhadap Gunung Merapi bahwa masyarakat percaya Gunung Merapi dihuni oleh para makhluk ghaib yang selayakmya memiliki kehidupan seperti manusia. Makhluk-makhluk ghaib tersebut terdapat organisasi tersendiri yang mengatur hirarki pemerintah dengan segala atribut dan aktivitasnya. Salah satu bentuk hirarki pemerintahan makhluk ghaib yang erat dihati masyarakat adalah masyarakat percaya bahwa Gunung Merapi merupakan Istana Makhluk Halus.
\end{abstract}

(C) 2019 Universitas Muria Kudus 
Permana, Septian Aji dan Hartanto, Supri

MITOLOGI SEBAGAI PENDIDIKAN KEBENCANAAN DALAM MEMAHAMI ERUPSI ...

REFLEKSI EDUKATIKA : Jurnal Ilmiah Kependidikan, Volume 9, Nomor 2, Juni 2019, hlm 121-127

\section{PENDAHULUAN}

Gunung Merapi sebagai salah satu unsur alam yang menjadi sumber kehidupan harus selalu diperhatikan dengan baik (Permana, 2016). Hal ini diperlukan agar hubungan antara masyarakat dengan alam tidak bersifat eksploitatif. Sebaliknya, hubungan ini lebih bersifat saling menjaga sehingga tercipta keselarasan. Masyarakat memiliki persepsi, bahwa siapa yang melanggar interaksi tersebut akan terkena hukuman.

Persepsi yang dimiliki masyarakat tentang kejadian erupsi tidak terlepas dari hukum sebabakibat. Masyarakat mempercayai ketika masyarakat tidak mau menjaga Gunung Merapi maka Merapi akan Murka (membawa ancaman), sedangkan ketika masyarakat mau menjaga Gunung Merapi maka Gunung Merapi akan membawa manfaat atau anugerah (Fatkhan, 2014). Persepsi ini sampai sekarang masih tetap sama, maka dari itu tidak heran jika Gunung Merapi masih dianggap keramat oleh masyarakat Cangkringan, hal ini karena sebagian besar masyarakat masih memegang teguh nilai-nilai luhur budaya Jawa dengan mempercayai adanya mitologi Gunung Merapi (Permana, 2016).

Hubungan antara Gunung Merapi, alam dan masyarakat Cangkringan seperti sudah menyatu. Muncul banyak mitos yang mengiringi hubungan tiga unsur tersebut. Walau tidak dapat dilogika dengan pikiran biasa banyak masyarakat yang percaya dengan mitos yang ada. Salah satu bentuk mitos yang masih tetap hidup dan tetap terpelihara dikalangan masyarakat adalah mitos tentang terjadinya letusan Gunung Merapi sebagai salah satu Gunung yang mempunyai kekuatan yang sangat besar, baik secara alami maupun karena mekanisme yang berlaku (Permana, 2016).

Masyarakat percaya sepenuhnya pada hukum pinasti atau takdir. Manusia meninggal, cidera, atau kehilangan harta benda karena bencana Gunung Merapi dipahami sebagai suatu takdir. Tahun 2010 Merapi meletus, laharnya menggenangi sungai dan sawah penduduk, namun masyarakat tetap menerima dengan besar hati (nrimo lan lilo). Kerugian sawah, ternak dan kebun justru disyukuri dengan ikhlas karena masyarakat percaya bahwa Gunung Merapi pasti akan mengganti dengan berlipat ganda. Hal ini dibuktikan Gunung Merapi meletus membawa material pasir dan batu yang bisa dimanfaatkan untuk sumber kehidupan selain itu abu Merapi bisa membawa kesuburan tersendiri untuk masyarakat petani atau berkebun (Permana, 2016).

Bagi masyarakat Cangkringan, Gunung Merapi melambangkan sebagai alat yang dapat memberikan manfaat dan ancaman. Gunung Merapi berperan penting dalam kehidupan masyarakat baik dalam segi ekonomi maupun segi sosial, dan budaya. Gunung Merapi, lingkungan, dan alam, serta kultur masyarakat Cangkringan merupakan satu kesatuan yang tidak dapat dipisahkan. Kesinambungan dan keselarasan kehidupan antara keempatnya tampak pada setiap kegiatan masyarakat. Penghargaan dan penghormatan terhadap Merapi dan alamnya selalu dikedepankan. Menurut kepercayaan masyarakat Cangkringan, Merapi dan alamnya adalah sesuatu yang patut dihormati dan dihargai (Walgito, 2004; Toha, 2003; Permana, 2016).

Gunung Merapi hingga saat ini masih dianggap sebagai gunung berapi yang aktif dan paling berbahaya di Indonesia, namun disisi lain masyarakat Cangkringan memiliki persepsi yang berbeda dengan masyarakat lereng Merapi lainnya, seperti masyarakat Magelang, Klaten, dan Boyolali bahwa mereka menganggap erupsi Merapi adalah suatu ancaman atau bahaya, berbeda dengan masyarakat Cangkringan yang menganggap erupsi Merapi bukan suatu ancaman atau bahaya melainkan suatu anugerah (Sugihartono, 2007; Siri, 2016).

Toha (2003) menyebut bahwa persepsi merupakan salah satu aspek psikologis yang penting bagi manusia dalam merespon kehadiran berbagai aspek dan gejala di sekitarnya. Walgito (2004), mengungkapkan bahwa persepsi merupakan suatu proses pengorganisasian, penginterpretasian terhadap stimulus yang diterima oleh organisme atau individu sehingga menjadi sesuatu yang berarti, dan merupakan aktivitas yang integrated dalam diri individu. Respon sebagai akibat dari persepsi dapat diambil oleh individu dengan berbagai macam bentuk. Stimulus mana yang akan mendapatkan respon dari individu tergantung pada perhatian individu yang bersangkutan. Berdasarkan hal tersebut, perasaan, kemampuan berfikir, pengalaman-pengalaman yang dimiliki individu tidak sama, maka dalam mempersepsi sesuatu stimulus, hasil persepsi mungkin akan berbeda antar individu satu dengan individu lain.

Persepsi masyarakat Cangkringan sampai sekarang masih tetap sama, bahwa keberadaan Gunung Merapi itu sebagai suatu anugerah. Masyarakat tetap tidak mau dipindahkan atau di 
Permana, Septian Aji dan Hartanto, Supri

MITOLOGI SEBAGAI PENDIDIKAN KEBENCANAAN DALAM MEMAHAMI ERUPSI ...

REFLEKSI EDUKATIKA : Jurnal Ilmiah Kependidikan, Volume 9, Nomor 2, Juni 2019, hlm 121-127

relokasikan, inilah sebuah bukti nyata kearifan masyarakat untuk selalu siap hidup bersahaja dengan alam, meskipun masyarakat Cangkringan berada pada posisi rentan, tetapi aktifitas seharihari masyarakat tetap berjalan (Rajib, 2001; Sebastian, 2001; Setyowati, 2014).

Fenomena ini dapat dipahami, sebagai sebuah sikap masyarakat Cangkringan untuk selalu siap hidup bersahaja dengan alam dan lingkungan yang mereka tempati, meskipun daerahnya telah hancur lebur dilalap api oleh awan panas dan dijadikan sebagai daerah terlarang serta tidak layak huni. Masyarakat Cangkringan menganggap bahwa lereng Gunung Merapi adalah tanah tumpah darah, sehingga Gunung Merapi dengan proses alaminya dirasakan sebagai sesuatu hal yang wajar (Permana, 2016).

\section{METODE PENELITIAN}

Penelitian ini menggunakan pendekatan kualitatif dengan metode etnofenomenologi. Penelitian dilakukan di Kecamatan Cangkringan, Yogyakarta. Alasan dipilihnya Kecamatan Cangkringan karena secara geografis wilayah Cangkringan sangat rentan terhadap ancaman erupsi Merapi namun masyarakatnya memiliki cara tersendiri dalam menghadapi erupsi Gunung Merapi.

Teknik pengumpulan data berupa observasi, wawancara, dan dokumentasi. Observasi dilakukan secara partisipatif, terus terang dan tersamar, serta tak terstruktur untuk mengetahui memastikan objek yang diteliti dalam hal ini informan berada di lokasi penelitian. Untuk memperoleh data yang lebih akurat dilakukan wawancara. Selanjutnya peneliti melakukan proses dokumentasi, pengarsipan, kemudian merakit sejumlah fakta dan informasi ke tingkat konsep dan teori.

Data yang diperoleh dianalisis dengan teknik analisis domain, taksonomik, komponensial dengan proses mengorganisasikan dan mereduksi data ke dalam pola, kategori dan satuan uraian dasar sehingga dapat ditentukan tema dan dapat dirumuskan suatu kesimpulan. Analisis tema kultur dilakukan pada saat pengumpulan data dan setelah selesainya pengumpulan data.

Pekerjaan analisis yang dilakukan dalam hal ini adalah mengatur, mengurutkan, memberi kode, dan mengkategorikan data sehingga dapat ditemukan deskripsi yang sesuai dengan aspek yang diteliti.

\section{HASIL DAN PEMBAHASAN}

1. Mitologi Masyarakat Dalam Memahami Bencana Erupsi Gunung Merapi

Gunung Merapi mempunyai peran yang besar baik secara mikrosmos dan makrosmos. Bagi masyarakat Gunung Merapi dianggap sebagai pemukiman para danyang dan ditunggu oleh roh-roh leluhur. Gunung Merapi menduduki posisi penting dalam mitologi masyarakat, diyakini sebagai pusat kerajaan makhluk halus, sebagai "swarga pengaratunan", dalam alur perjalanan hidup yang digambarkan dengan sumbu imajiner dan garis spiritual kelanggengan yang menghubungkan Laut Kidul, Panggung Krapyak, Kraton Yogyakarta, Tugu Pal Putih dan Gunung Merapi. Simbol ini serat dengan makna tentang proses kehidupan manusia dari lahir sampai menghadapi kepada Sang Maha Pencipta.

Masyarakat percaya bahwa selain manusia, dunia dan alam semesta juga dihuni oleh makhluk-makhluk ghaib yang selayaknya memiliki kehidupan seperti manusia. Makhluk-makhluk ghaib tersebut terdapat organisasi tersendiri yang mengatur hirarki pemerintahan dengan segala atribut dan aktivitasnya. Salah satu bentuk hirarki pemerintahan makhluk ghoib yang erat di hati masyarakat adalah istana makhluk ghaib.

Hubungan antara Gunung Merapi, alam. dan masyarakat Cangkringan seperti sudah menyatu. Muncul banyak mitos yang mengiringi hubungan tiga unsur tersebut. Walau tidak dapat dilogika dengan pikiran biasa banyak masyarakat yang percaya dengan mitos yang ada. Salah satu bentuk mitos yang masih tetap hidup dan tetap terpelihara di kalangan masyarakat yang menyakini adalah mitos tentang keraton mahluk halus Merapi.

Kepercayaan serta kosmologi Gunung Merapi didasarkan dalam mitos Kyai Sapujagad. Mitos ini muncul pada waktu awal Kerajaan Mataram kedua yang menggambarkan hubungan pendiri kerajaan Panembahan Senopati dengan dunia ghaib. Suryo (2019) menuturkan bahwa Gunung Merapi pada masa ketika kerajaan dari Mataram masih diperintah oleh Panembahan Senopati terjadi peperangan dengan India. Kemudian Mataram kalah jatuh di Laut Selatan. Di Laut Selatan inilah kemudian Panembahan Senopati dipertemukan dengan Ratu Kidul. Yang akhirnya Ratu Kidul ini 
mau dipersunting oleh Raja. Dari perjanjiannya tersebut dapat diungkap bahwa Ratu Kidul bersedia diperistri oleh Penembahan Senopati beserta seluruh Rajaraja penerus Mataram lainnya dan ia bersedia menjaga keselamatan Kerajaan Mataram dari ancaman badai Laut Selatan.

Pada pertemuan di Pleret tersebut Panembahan Senopati diberikan sebutir endhog jagad (telur dunia) oleh Kanjeng Ratu Kidul untuk dimakan. Namun beliau tidak langsung memakannya akan tetapi telur tersebut dibawanya pulang. Sesampainya di rumah rumah telur tersebut diberikan kepada Ki Juru Taman, seseorang abdi dalem yang dikenal sangat setia kepada Panembahan Senopati.

Ki Juru Taman langsung memakan telur tersebut, kemudian Ki Juru Taman berubah menjadi raksasa yang badan raganya berubah menjadi mahluk halus yang berwujud raksasa. Untuk menyembunyikan rasa malu akibat dari perubahan tersebut, kemudian Panembahan Senopati menempatkan Ki Juru Taman di Gunung Merapi dengan gelar Kyai Sapujagad tugasnya adalah menjaga Raja beserta isi Keraton dari amukan Gunung Merapi. Panembahan Senopati berjanji setiap tahunnya akan selalu mengirim kebutuhan $\mathrm{Ki}$ Juru Taman di Merapi, yang kemudian dikenal dengan upacara Labuhan.

Akibat dari legenda Kyai Sapujagad adalah bahwa Keraton Mataram Yogyakarta bertanggungjawab untuk memberi sesaji kepada para mahluk halus di empat tempat yang lain dalam kosmologi manusia. Dalam kembalinya rakyat akan dilindungi oleh para mahluk halus tersebut. Perjanjian itu berbentuk Upacara Labuhan yang dilakukan setiap tahun sekali dan mulai tanggal 25 bulan Bakdamulud untuk meminta keselamatan dari marabahaya ancaman erupsi Gunung Merapi.

Masyarakat percaya jika Gunung Merapi merupakan keraton makhluk halus yang merupakan komunitas arwah warga yang tatkala hidup di dunia melakukan amal yang baik. Sedangkan bagi mereka yang banyak melakukan kejahatan sesama hidupnya, rohnya melayang-layang ke barat dan ke timur tanpa tujuan "nglambrang" ke mana-mana lalu biasanya akan menghuni dibebatuan yang besar, pohon-pohon besar, jembatan dan menjadi penunggu tempat tersebut.

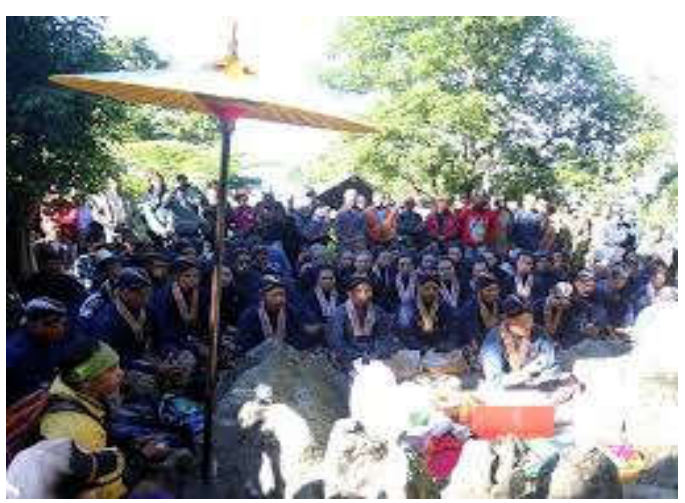

Gambar 1. Prosesi Upacara Labuhan (Sumber Foto: Arsip Museum Merapi, 2018)

Keraton mahluk halus Gunung Merapi di dalam kosmologi keraton Yogyakarta dipercayai oleh masyarakat dipimpin oleh mahluk halus bernama Empu Rama dan Permadi. Masyarakat percaya bahwa, jika Gunung Merapi sedang mengeluarkan asap tebal (awan panas), maka secara mitologi menurut masyarakat dapat dipahami kalau makhluk ghaib yang ada di Gunung Merapi sedang "Duwe Gawe" (sedang punya hajat). Maka dari itu masyarakat dihimbau untuk menjauh dari Gunung Merapi karena makhluk ghaib yang sedang punya hajat tidak mau diganggu.

Selain pemimpin di keraton Gunung Merapi juga terdapat beberapa tokoh atau danyang yang Menjaga Gunung Merapi yang lain. Seperti Nyai Gadung Melati sesuai gambarnya warna "Gudung Melati" atau warna hijau pupus, adalah warna kesayangan nyai Gadung Melati yang bertugas memelihara sekitar Merapi. Nyai Gandung Melati adalah tokoh yang paling terkenal dan dicintai oleh masyarakat. Dia berperan sebagai komandan pasukan makhluk halus Merapi dan tinggal di Gunung Wutoh, pintu gerbang utama Keraton Merapi. Tokoh ini bertugas memelihara kehijauan tanaman Gunung Merapi.

Tokoh mahluk halus yang lainnya adalah Eyang Sapujagad yang tinggal di Pasar Bubrah di bawah kawah dan berperan mengatur keadaan alam Merapi. Eyang Sapujagad adalah kunci penentu meletus tidaknya Gunung Merapi. Eyang Sapujagad memiliki anak buah seperti Kyai Krinci Wesi dan Branjang Kawat. Maka setiap Labuhan Keraton Yogyakarta ditunjukan kepada Kyai 
Permana, Septian Aji dan Hartanto, Supri

MITOLOGI SEBAGAI PENDIDIKAN KEBENCANAAN DALAM MEMAHAMI ERUPSI ...

REFLEKSI EDUKATIKA : Jurnal Ilmiah Kependidikan, Volume 9, Nomor 2, Juni 2019, hlm 121-127

Sapujagad beserta onderbounya. Eyang Sapujagad kita maknai sebagai kawah lava ketika kawah tersebut meletup keluar maka Gunung Merapi meletus.

Tokoh Kyai Petruk yang dikenal sebagai salah satu prajurit Gunung Merapi, yang sangat diharapkan kedatangannya saatsaat kritis, karena sifatnya yang "tumbak cucukan" alias melapor hal yang detail sekalipun. Melalui mimpi ia akan menjelaskan caranya menyelamatkan diri saat Merapi membuang kotorannya. Ketika Kyai Petruk keluar terompet dibunyikan atau masyarakat mengenal dengan suara gemuruh gludug gludug gludug, hal ini menandakan Gunung Merapi akan meletus.

Tokoh mahluk halus yang bertugas mengatur cuaca dan udara Gunung Merapi, bernama Eyang Megantara, yang kadang menampakkan diri sebagai seorang yang berkendaraan kuda. Itu sebabnya dalam upacara Labuhan Keraton Yogyakarta, diselipkan seperangkat pakaian kuda bernama Kyai Cekatidak. Dimaknai oleh masyarakat ketika Gunung Merapi bersetatus waspada maka suhu akan naik sehingga masyarakat harus segera mengambil sikap.

\section{Makna Pendidikan yang Tersirat di Dalam Mitologi Gunung Merapi}

Memahami mitologi Gunung Merapi tidak terlepas dari filosofi kota Yogyakarta dengan Kraton Ngayogyakarta Hadiningrat sebagai pancernya. Kota ini terbelah oleh sumbu imajiner yang menghubungkan Laut Kidul, Parangkusumo, Panggung Krapyak, Keraton, Tugu Pal Putih dan Gunung Merapi. Secara filosofis hal ini dibagi menjadi dua aspek, yaitu Jagat Alit dan Jagat Ageng.

Jagat Alit yang mengurai proses awalakhir hidup dan kehidupan manusia dengan segala prilaku yang lurus sehingga terpahaminya hakekat hidup dan kehidupan manusia, digambarkan dengan planologi kota Yogyakarta sebagai kota Raja pada waktu itu. Planologi kota ini membujur dari selatan ke utara berawal dari Panggung Krapyak berakhir di Tugu Pal Putih. Hal ini menekankan hubungan timbal balik antara Sang Pencipta dan Manusia sebagi Penciptaanya.

Gunung Merapi, dilukiskan sebagai perlambangan alat keperkasaan pria "lingga", melainkan dipandang para spiritualis sebagai kerajaan para spirit yang jumlahnya ada sembilan makhluk, dengan tugasnya masingmasing. Sementara pasangannya adalah Laut Selatan yang dilukiskan sebagai "Yoni" maka jika dua perlambang ini bersatu, munculah konsep "sangkan paraning dumadi". Mengandung pengertian hubungan horizontal antara sesama makhluk ciptaan Sang Pencipta, yang di gambarkan hubungan simbolik antara Gunung Merapi, Keraton Yogjakarta dan Laut Selatan.

Perjalanan hidup, manusia tergoda oleh berbagai macam kenikmatan duniawi, dapat berupa wanita dan harta digambarkan dalam bentuk pasar Beringharjo. Sedangkan godaan akan kekuasaan digambarkan oleh komplek Kepatihan yang semuanya berada pada sisi kanan pada jalan lurus anatara Keraton dan Tugu Pal Putih, sebagai lambang manusia yang dekat dengan pencipta-Nya (Manunggal kawula gusti).

Jagat Ageng yang mengurai tentang hidup dan kehidupan masyarakat, siapapun yang menjadi pemimpin masyarakat senantiasa menjadikan hati nurani rakyat sebagai istri pertama dan utama untuk mewujudkan kesejahteraan lahir batin bagi masyarakat yang dilandasi dengan keteguhan dan kepercayaan bahwa hanya satu pencipta Yang Maha Besar. Jagat Ageng ini digambarkan dengan garis imajiner dari Parangkusumo di Laut Selatan, Keraton Yogyakarta dan Gunung Merapi.

Makna yang bisa dipetik adalah bahwa alam merupakan ciptaan Tuhan yang harus kita jaga dan kita hormati. Seperti halnya alam juga seperti manusia yang memiliki hasrat ingin dimengerti dan ingin dihormati. Ada hubungan timbal balik antara alam dan manusia ketika alam menyediakan semua kebutuhan manisia selayaknya manusia harus mau menjaga dan melestarikan alam agar alam tidak murka kepada manusia.

Dari kepercayaan seperti ini, dapat di analisis bahwa kepercayaan masyarakat terhadap kosmologi Merapi, keraton mahluk halus Gunung Merapi, dan tempat angker bukan saja hanya sebuah mitos akan tetapi memang penting untuk keselamatan masyarakat. Kepercayaan terhadap Gunung Merapi merupakan ungkapan kebijaksanaan hidup masyarakat terhadap lingkungan setempat, suatu bentuk penghormatan terhadap Tuhan YME dan roh-roh para leluhur, dengan harapan mendapat balas jasa 
Permana, Septian Aji dan Hartanto, Supri

MITOLOGI SEBAGAI PENDIDIKAN KEBENCANAAN DALAM MEMAHAMI ERUPSI ... REFLEKSI EDUKATIKA : Jurnal Ilmiah Kependidikan, Volume 9, Nomor 2, Juni 2019, hlm 121-127

berupa keselamatan, kesuburan dan kesejahteraan.

Bentuk penghormatan masyarakat ini mengingatkan bahwa manusia akan mati dan menjadi roh seperti para leluhur, oleh karena itu dalam hidupnya manusia harus mengembangkan kehidupan yang baik tehadap lingkungan sesamanya, alam dan alam adi kodrati. Hal ini terungkap dalam kepercayaan masyarakat akan hirarki dan penempatan roh leluhur di keraton mahluk halus Gunung Merapi, sesuai dengan kelakuan dan tindakan serta pekerjaan selama hidup. Semua pesan kalau kita maknai penuh mengandung pesan filosofis untuk hidup selalu bersahaja dengan alam dan lingkungan yang kita tempat.

Hasil riset ini senada dengan penelitian Wibowo, Wasino, dan Setyowati (2012) yang menujukkan ada peranan perlindungan lingkungan yang dilakukan oleh masyarakat desa Colo berkaitan dengan kearifan lokal yang berhubungan dengan kepercayaan masyarakat setempat akan kekuatan diluar manusia yang turut menjaga kelestarian lingkungan. Masyarakat desa Colo sudah melakukan prinsip-prinsip etika lingkungan hidup, berupa norma peran untuk menjaga kawasan hutan Muria. Strategi masyarakat desa Colo dalam melindungi Kawasan Hutan Muria, membentuk organisasi lokal yang peduli terhadap lingkungan yaitu PMPH (Paguyuban Masyarakat Pelindung Hutan).

Hasil penelitian ini memiliki kesamaan dengan riset Sufia, Sumarmi, dan Amirudin (2016) yang menunjukkan bahwa masyarakat adat memiliki kehidupan yang sederhana, harmonis, dan secara tidak sadar kepercayaan mereka tentang situs Buyut Cili mampu berperan dalam melestarikan lingkungan hidupdi wilayah tersebut, seperti; sumber air, area persawahan, dan ladang.

Hasil riset ini senada pula dengan penelitian Ismaya, Permana, dan Setyowati (2017) yang menyatakan bahwa berdasarkan topografi wilayah Dukuh Masin, lahir sebuah cerita rakyat Raden Ayu Nawangsih dan Raden Bagus Rinangku. Pada hakekatnya, cerita rakyat ini merupakan sebuah upaya melestarikan lingkungan.

\section{SIMPULAN}

Sepanjang sejarah manusia yang hidup berdampingan bersama alam sering mengalami bencana, seperti letusan Gunung Merapi. Bencana tersebut sangat berhubungan dengan tindakan manusia, karena manusia tidak dapat memisahkan diri dengan dunia manusia, dan alam, semua adalah satu. Sehingga kejadiankejadian yang terjadi dalam dunia manusia, merupakan refleksi dari kejadian alam.

\section{DAFTAR PUSTAKA}

Fatkhan, Muhammad. 2014. Kearifan Lingkungan Masyarakat Lereng Gunung Merapi dalam Menjaga Alam. Jurnal: Penaggulangan Bencana, 5 (1).

Glenn Fernandez and Shaw Rajib. 2013. Youth Council Participation in Disaster Risk Reduction in Infanta and Makati, Philippines: A Policy Review. Jurnal: Disaster Risk Science, 4 (3): 126-136.

Glik Deborah, David, Eisenman, Zhou Qiong. 2014. Using the Precaution Adoption Process Model to Describe A Disaster Preparedness Intervention Among Lowincome Latinos. Jurnal: Health Education Research, 29 (2): 272-283.

Hiryanto. 2013. Local Wisdom Identification on Understanding Natural Disaster Signs By Elders In Daerah Istimewa Yogyakarta. Jurnal: Penaggulangan Bencana, 4 (1).

Ismaya, Erik Aditia., Permana, Septian Aji., dan Setyowati, Dewi Liesnoor. 2017. MAKNA DIBALIK LEGENDA: Kearifan Lokal Masyarakat Masin dalam Melestarikan Lingkungan. Prosiding Seminar Nasional Pembelajaran Bahasa dan Sastra Indonesia Berbasis Kearifan Lokal dalam Pembentukan Karakter Bangsa. Kudus: Universitas Muria Kudus.

Permana Septian Aji. 2016. Petuah Merapi Sebagai Kearifan Masyarakat untuk Kesiapsiagaan Menghadapi Ancaman Bencana Erupsi Gunung Merapi di Wilayah Cangkringan, Yogyakarta. Draf Disertasi. Semarang: UNNES

Pohan. 2006. Kerangka Aksi Hyogo: Pengurangan Risiko Bencana 2005-2015 membangun Ketahanan Bangsa dan Komunitas Terhadap Bencana. Terjemahan oleh 
Permana, Septian Aji dan Hartanto, Supri

MITOLOGI SEBAGAI PENDIDIKAN KEBENCANAAN DALAM MEMAHAMI ERUPSI ...

REFLEKSI EDUKATIKA : Jurnal Ilmiah Kependidikan, Volume 9, Nomor 2, Juni 2019, hlm 121-127

Wuryanti T. Jakarta: Masyarakat Penanggulangan Bencana Indonesia.

Prajanti, Sucihatiningsuh Dian Wisika. 2013. Evolution On Benefits And Development Of Information and Communication Technology (ICT) To Improve The Perfomance Of Agricultur Extension In Sentral Java. Internasional Journal. Organization Innovation (Online) 6 (2): 243-253.

Rajib Shaw and Takeuchi Yukiko. 2001. Sustainable Community Disaster Education in Saijo City and its Effectiveness in Landslide Risk Reduction. Jurnal: Springer Science \& Business Media.

Setyowati Dewi Liesnoor. 2014. Public Perception of Disaster Landslides and Efforts to Overcome in Subdistrict Kaloran Central Java. Universal Journal of Geoscience, 2 (7): 195-199.

Siri Hettige. 2016. An Integrated Social Response to Disasters: The Case of The Indian Ocean Tsunami in Sri Lanka. Disaster Prevention and Management: An International Journal, 25 (5): 628-648.
Sufia, Rohana., Sumarmi, S., dan Amirudin, Ach. 2016. Kearifan Lokal Dalam Melestarikan Lingkungan Hidup (Studi Kasus Masyarakat Adat Desa Kemiren Kecamatan Glagah Kabupaten Banyuwangi). Jurnal Pendidikan: Teori, Penelitian, dan Pengembangan, 1 (4): $726-731$.

Sugihartono. 2007. Persepsi dan Kepercayaan. Yogyakarta: Kanisius.

Swasono, Meutia Farida. 1995. Peranan dan Kontribusi Usia Lanjut. Laporan Penelitian. Jakarta: FISIP UI.

Toha Miftah. 2003. Sistem dan Mekanisme Persepsi Orang Jawa. Yogyakarta: Kanisius.

Walgito Bimo. 2004. Persepsi Masyarakat Pedesaan. Yogyakarta: Pustaka Pelajar.

Wibowo, Hendro Ari., Wasino, Wasino., dan Setyowati, Dewi Liesnoor. 2012. Kearifan Lokal Dalam Menjaga Lingkungan Hidup (Studi Kasus Masyarakat Di Desa Colo Kecamatan Dawe Kabupaten Kudus). Journal of Educational Social Studies, 1(1). Retrieved from https://journal.unnes.ac.id/sju/index.php/j ess/article/view/79 